Bangladesh J. Bot. 44(3): 407-413, 2015 (September)

\title{
ISSR-BASED GENETIC DIVERSITY OF WILD AND EX SITU CONSERVED POPULATION OF HOPEA CHINENSIS (MERR.) HAND.-MAZZ
}

\author{
Wen-Xiu Tang, Wan-Juan Dai, Xing-Hua Hu and Shi-Xun Huang* \\ Guangxi Institute of Botany, the Chinese Academy of Sciences, Guilin 541006, China
}

Key words: Hopea chinensis, Wild population, Ex situ conservation, ISSR, Genetic diversity

\begin{abstract}
The genetic diversity and structure of 4 wild population and 2 ex situ conserved population of Hopea chinensis (Merr.) Hand.-Mazz were analyzed and compared by ISSR marker method. Fifty eight bands were amplified from total genomic DNA with 10 primers in which there were 51 polymorphic, the percentage of polymorphic bands of populations ranged from 53.45 to 79.31 , with an average value of 69.82, indicating the presence of high genetic diversity. However, the percentage of polymorphic band, Nei's diversity index (He) and Shannon information index (I) of wild populations (86.21, 0.3636 and 0.5232 , respectively) were higher than those of ex situ conservated populations (77.59, 0.3153 and 0.4597 , respectively), which meant that $e x$ situ conservations of Hopea chinensis had a narrow genetic diversity. Population structure analysis revealed that genetic variation of Hopea chinensis was 0.0373 , so the genetic differentiation was $3.73 \%$ among populations, and $96.27 \%$ in populations. Furthermore, the strong gene flow $(\mathrm{Nm}=12.8896)$ would be the main reason of limited population differentiation. It concluded that ex situ population had not yet fully covered the entire genetic diversity of Hopea chinensis.
\end{abstract}

\section{Introduction}

Hopea chinensis (Merr.) Hand.-Mazz, a tertiary relict plant unique to China, is distributed only in Daqingshan Mountain and Shiwandashan Mountain (both located in China's southern province Guangxi) (Xu and Yu 1982). It commonly grows on low mountain and in valley, regarded as one of the typical tree species in evergreen monsoon forest of southern Guangxi (Wang et al. 1994). It is also one of the most valuable timber tree species in Guangxi for its wood has a great economic value in architecture, shipbuilding and furniture manufacturing. However, Hopea chinensis is being destroyed at an alarming rate due to serious ecological environmental destruction, and has been listed as the first degree of national protection plant (Yu 1999).

In recent years, global biodiversity declined drastically, lots of plant species are estimated to be threatened with extinction (IUCN 2006). Ex situ conservation, as an efficient approach with the main goal of maintaining optimum genetic diversity for rare and endangered plant species has been adopted worldwide (Frankham et al. 2002). From 1990s, ex situ conservation program began to carry out for Hopea chinensis (Zhang et al. 2001), and two ex situ methods of conservation have been established in Guilin city, Guangxi Province and in Xisuangbanna County, Yunnan Province. Some individuals have been successfully blossomed and fruited, due to newly adopted methods conservation. Research on ex situ conservation of cultivated Hopea chinensis is progressing. Most of these studies however, are only focused on observing characteristics of growth and fruitage of ex situ conserved populations, not involving conservation genetics (Tang et al. 2009, Huang et al. 2008, Zhou et al. 2013). Studying the genetic characteristics is essential for the establishment of effective and efficient conservation practices for rare plants (Yang et al. 2010). Molecular markers such as inter-simple sequence repeats (ISSR) have been proposed an

*Author for correspondence: $<$ hsx @ gxib.cn>. 
economical and reliable DNA marker system (Zietkiewicz et al. 1994), and widely used for analyses on genetic diversity and phylogenetic relationship in multiple species (Zhou et al. 1999, Culley et al. 2007, Zhang et al. 2008).

In this study, the main objectives were to discriminate and evaluate the genetic diversity and structure of Hopea chinensis from 4 wild populations and 2 ex situ conserved populations by using ISSR molecular marker technology. Our study may have important implications for further work on ex situ conservation.

\section{Materials and Methods}

Leaf samples of Hopea chinensis were originally collected from 4 wild populations (Naqin, Fulong, Nasuo and Gongyuan) in Shiwandashan mountain, Fangchenggang city, Guangxi Zhuang Autonomous Region, China, and 2 ex situ conserved populations (Guilin botanic garden and Xishuangbanna botanic garden), China (Table 1). Each wild population was represented by 20 individuals. For ex situ conserved populations, only 20 samples were obtained, due to their tiny habitat.

Table 1. Profiles of sampling population.

\begin{tabular}{lllcc}
\hline Population & & Latitude & Altitude /m & Sample number \\
\hline \multirow{4}{*}{ Wild population } & Naqin (NQ) & N21 $52^{\circ}$ E108 $01^{\prime}$ & 180 & 20 \\
& Fulong (FL) & N21 $50^{\circ}$ E107 $55^{\prime}$ & 193 & 20 \\
& Nasuo (NS) & N21 $45^{\prime}$ E108 $06^{\prime}$ & 60 & 20 \\
Ex situ conservated & Gongyuan (GY) & N21 $54^{\circ}$ E107 $54^{\prime}$ & 284 & 20 \\
populations & Guilin (GL) & N25 $01^{\prime}$ E110 $17^{\prime}$ & 170 & 10 \\
\hline
\end{tabular}

Leaves were desiccated in silica gel before DNA extraction. Total genomic DNA was extracted following the modified CTAB method described by Dai et al. (2011). The concentration of DNA was estimated by spectrophotometer and the quality was checked using $0.8 \%$ agarose gel electrophoresis.

ISSR primers published by the University of British Columbia (UBC, Zuo et al. 2001) were used. One hundred ISSR primers were initially screened, of which 10 yielded bright and discernible bands were selected to further analyze genetic diversity of our samples. ISSR amplifications were performed in a $25 \mu$ reaction volume containing $1 \times$ PCR buffer, $2.0 \mathrm{mM}$ $\mathrm{Mg}^{2+}, 0.25 \mathrm{mM}$ dNTP, $0.4 \mathrm{U}$ Taq polymerase, $0.2 \mu \mathrm{M}$ primer, and $4 \mathrm{ng}$ template DNA. The PCR reaction was programmed as follows: initial denaturation at $94^{\circ} \mathrm{C}$ for $5 \mathrm{~min}, 35$ cycles of $94^{\circ} \mathrm{C}$ for $45 \mathrm{~s}$, primer annealing at $53^{\circ} \mathrm{C}$ for $45 \mathrm{~s}$, extension at $72^{\circ} \mathrm{C}$ for $1.5 \mathrm{~min}$, and a final extension at $72^{\circ} \mathrm{C}$ for $7 \mathrm{~min}$ (Dai et al. 2011). Amplification products were separated in $1.5 \%$ agarose gels buffered with $1 \times \mathrm{TAE}$ and stained with ethidium bromide.

ISSR profiles were scored for each individual as the presence (1) or absence (0) of specific bands and entered into a binomial matrix. A measure of intra- and inter-population genetic statistics were then calculated by "POPGENE32" (Yeh et al. 1999), including the percentage of polymorphic bands (PPB), number of alleles $(\mathrm{Na})$, effective allele number $(\mathrm{Ne})$, total genetic diversity (Ht), intra-population genetic diversity $(\mathrm{Hs})$, Nei's gene diversity $(\mathrm{He})$ and Shannon's information index (I) and the relative magnitude of genetic differentiation among population (Gst $=\mathrm{Ht}-\mathrm{Hs} / \mathrm{Ht})(\mathrm{Nei}$ and $\mathrm{Li}$ 1979). Gene flow was estimated using the formula: $\mathrm{Nm}=(1-\mathrm{Gst}) / 4 \mathrm{Gst}$ (Slatkin and Barton 1989). A dendrogram was constructed to evaluate the genetic relationship for 
these populations by the unweighted pair group method with arithmetic average (UPGMA), based on the average genetic distances, with the SAHN module of NTSYS-pc 2.10 (Rohlf 2000).

\section{Results and Discussion}

Ten ISSR primers chosen for analysis produced a total of 58 bands, of which 51 were polymorphic, the percentage of polymorphism of the amplified products was 87.93 (Table 2). The number of bands per primer ranged from 4 to 7 with the average number of bands per primer being 5.8. The size of DNA fragments ranged from 400 to $2000 \mathrm{bp}$. The genetic diversity of the 6 populations showed that the percentage of polymorphic bands ranged from 53.45 to 79.31 with a average of 69.82 between populations. The ISSR patterns of PCR amplified by primer UBC825 is presented in Fig. 1.

Table 2. The sequences and amplifying results of 10 ISSR primers.

\begin{tabular}{llcc}
\hline $\begin{array}{l}\text { Primer } \\
\text { code }\end{array}$ & $\begin{array}{l}\text { Primers } \\
\text { sequence }\end{array}$ & $\begin{array}{c}\text { No. of } \\
\text { amplified bands }\end{array}$ & $\begin{array}{c}\text { No. of } \\
\text { polymorphic bands }\end{array}$ \\
\hline UBC811 & $\mathrm{G}(\mathrm{Ag})_{7} \mathrm{AC}$ & 5 & 5 \\
$\mathrm{UBC} 813$ & $\mathrm{C}(\mathrm{TC})_{7} \mathrm{TT}$ & 5 & 5 \\
UBC815 & $\mathrm{C}(\mathrm{TC})_{7} \mathrm{Tg}$ & 6 & 3 \\
$\mathrm{UBC} 818$ & $\mathrm{C}(\mathrm{AC})_{7} \mathrm{Ag}$ & 6 & 6 \\
$\mathrm{UBC} 825$ & $\mathrm{~A}(\mathrm{CA})_{7} \mathrm{CT}$ & 7 & 7 \\
UBC827 & $\mathrm{A}(\mathrm{CA})_{7} \mathrm{Cg}$ & 7 & 7 \\
UBC841 & $\mathrm{G}(\mathrm{Ag})_{7} \mathrm{AYC}$ & 4 & 0 \\
UBC857 & $\mathrm{A}(\mathrm{CA})_{7} \mathrm{CYg}$ & 5 & 5 \\
UBC886 & $\mathrm{VDVC}(\mathrm{TC})_{6} \mathrm{~T}$ & 6 & 6 \\
UBC890 & $\mathrm{VHVg}(\mathrm{Tg})_{6} \mathrm{~T}$ & 7 & 7 \\
Total & $/$ & 58 & 51 \\
Average & $/$ & 5.8 & 5.1 \\
\hline
\end{tabular}

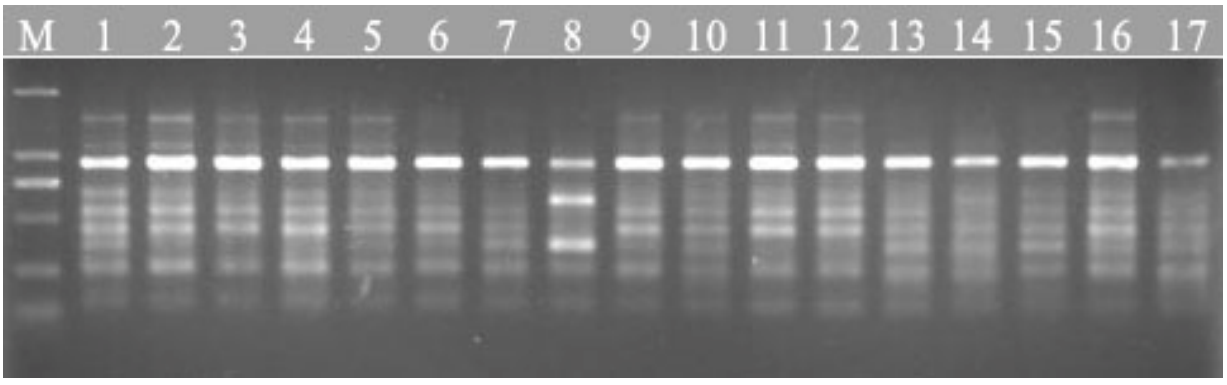

Fig. 1. Electrophoresis picture of PCR products from primer UBC825. Lane 1 - 10 and 11 - 17, were the individuals of Hopea chinensis in Guilin and Xishuanbanna, respectively, $\mathrm{M}$ indicates DNA marker.

The number of alleles (Na) per population ranged from 1.5345 to 1.7931, with an average of 1.6983. The effective number of alleles (Ne) ranged from 1.4487 to 1.6737 , with an average of 1.6671. At the species level, the percentage of polymorphic bands (PPB), Nei's diversity index (He) and Shannon's information index (I) were 87.93, 0.3637 and 0.5242 , respectively. Among six populations, the Shannon diversity index (I) averaged 0.4516 with a range from 0.3431 to 0.5126 . 
He and I together showed that the corresponding variation order of the populations was Fulong $(\mathrm{FL})>$ Gongyuan $(\mathrm{GY})>$ Nasuo $(\mathrm{NS})>$ Xishuangbanna $(\mathrm{BN})>$ Naqin $(\mathrm{NQ})>$ Guilin $(\mathrm{GL})$. The percentage of polymorphic bands (PPB), Nei's gene diversity (He) and the Shannon diversity index (I) of these populations had the same tendency, except Naqin (NQ) and Xishuangbanna (BN). These indexes indicated that wild populations had a larger genetic diversity compared with to ex situ conservated populations (Table 3).

Table 3. Genetic diversity among six populations of Hopea chinensis.

\begin{tabular}{llcccccc}
\hline Population & & $\mathrm{Na}$ & $\mathrm{Ne}$ & $\mathrm{He}$ & $\mathrm{I}$ & $\begin{array}{c}\text { Polymorphic } \\
\text { bands }\end{array}$ & $\begin{array}{c}\text { poly- } \\
\text { morphism/\% }\end{array}$ \\
\hline Wild population & NQ & 1.7069 & 1.5729 & 0.3120 & 0.4466 & 41 & 70.69 \\
& FL & 1.7931 & 1.6737 & 0.3608 & 0.5126 & 46 & 79.31 \\
& $\mathrm{NS}$ & 1.7241 & 1.6251 & 0.3319 & 0.4704 & 42 & 72.41 \\
& $\mathrm{GY}$ & 1.7414 & 1.6459 & 0.3428 & 0.4851 & 43 & 74.14 \\
& Total & 1.8621 & 1.6688 & 0.3636 & 0.5232 & 50 & 86.21 \\
Ex situ conservated & GL & 1.5345 & 1.4487 & 0.2411 & 0.3431 & 31 & 53.45 \\
populations & BN & 1.6897 & 1.5983 & 0.3193 & 0.4519 & 40 & 68.97 \\
Average & Total & 1.7759 & 1.5597 & 0.3153 & 0.4597 & 45 & 77.59 \\
Species level & & 1.6983 & 1.5941 & 0.3180 & 0.4516 & 40.5 & 69.82 \\
\hline
\end{tabular}

The total gene diversity $(\mathrm{Ht})$, genetic diversity within populations $(\mathrm{Hs})$ and the genetic differentiation coefficient (Gst) among 6 populations indicated that the genetic diversification intra-population was far greater than that of inter-populations, and gene flow $(\mathrm{Nm}=12.8896)$ was high among populations of Hopea chinensis (Table 4).

Table 4. Genetic diversity and differentiation parameters between wild populations and ex situ conserved populations.

\begin{tabular}{lcccc}
\hline Population & $\mathrm{Ht}$ & $\mathrm{Hs}$ & $\mathrm{Gst}$ & $\mathrm{Nm}$ \\
\hline Group of wild populations & 0.3636 & 0.3369 & 0.0735 & 6.3020 \\
Group of ex situ conservated populations & 0.3153 & 0.2802 & 0.1112 & 3.9974 \\
Total & 0.3610 & 0.3475 & 0.0373 & 12.8896 \\
\hline
\end{tabular}

The Nei's genetic distance (D) and genetic similarity coefficient among six populations were shown in Table 5. The genetic similarity coefficient ranged from 0.8957 to 0.9554 , and the Nei's genetic distance (D) ranged from 0.0456 to 0.1101 , with the farthest $(0.1101)$ being between Guilin (GL) and Nasuo (NS), and the nearest (0.0456) being between Gongyuan (GY) and Nasuo (NS). An inverse relationship was found for genetic similarity coefficient. The average genetic distance among ex situ conservated populations $(\mathrm{D}=0.0922)$ was higher than that among wild populations $(\mathrm{D}=0.0550)$, which indicated a certain variation seems to be happening in ex situ conservated populations. 
Table 5. Genetic similarity coefficient (above diagonal) and genetic distance (below diagonal) of Hopea chinensis.

\begin{tabular}{lcccccc}
\hline Population & NQ & FL & NS & GY & GL & BN \\
\hline NQ & $* * * *$ & 0.9494 & 0.9483 & 0.9426 & 0.9016 & 0.9086 \\
FL & 0.0519 & $* * * *$ & 0.9402 & 0.9427 & 0.9221 & 0.9305 \\
NS & 0.0530 & 0.0616 & $* * * *$ & 0.9554 & 0.8957 & 0.9261 \\
GY & 0.0591 & 0.0590 & 0.0456 & $* * * *$ & 0.9105 & 0.9078 \\
GL & 0.1036 & 0.0811 & 0.1101 & 0.0937 & $* * * *$ & 0.9039 \\
BN & 0.0959 & 0.0720 & 0.0768 & 0.0967 & 0.1010 & $* * * *$ \\
\hline
\end{tabular}

NQ, FL, NS and GY corresponding to 4 wild populations, BN and GL corresponding to 2 Ex situ conservated populations listed in Table 1 .

The cluster results showed that populations with lower genetic distance (GY and NS) were grouped together, and then grouped together with NQ and FL. In addition, BN and GL formed independently group (Fig. 2). Indicated the genetic variation inter-population was consistent with its geographic distribution.

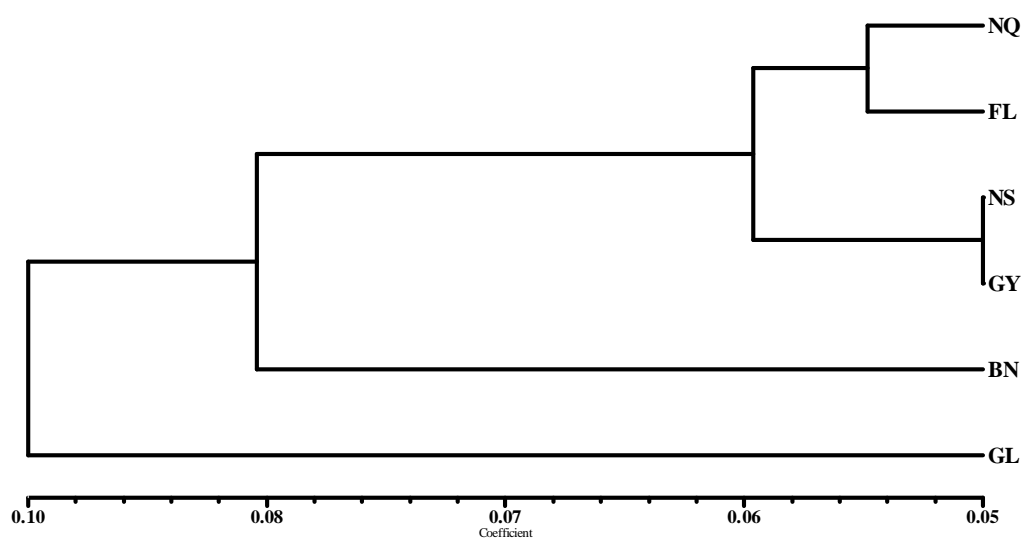

Fig. 2. UPGMA dendrogram of six pupulations of Hopea chinensis. NQ, FL, NS and GY corresponding to 4 wild populations, BN and GL corresponding to 2 ex situ conservated populations listed in Table 1.

In conclusion, knowing the levels of genetic diversity is significant for planning conservation strategies for rare and endangered species. Based on ISSR in this study, the wild populations was found to have a high genetic diversity $(\mathrm{PPB}=77.59 \%, \mathrm{H}=0.3153, \mathrm{I}=0.4597$ ). However, relatively lower genetic diversity was found among ex situ conservated populations (PPB = $86.21 \%, \mathrm{H}=0.3636, \mathrm{I}=0.5232$ ) compared with the wild populations. This might be resulted from the small population size of ex situ conservation, in which the individuals only covered a limited set of wild population resources. It meant though the introduced Hopea chinensis had been proved to grow and fruit normally in these two ex situ methods conservation, but it is still not sufficient, especially on genetic diversity. The mean Gst value (0.0373) across all populations indicated that only $3.73 \%$ of the total genetic variation resides among populations of this species, it suggested that develop a conservation plan could focuses on representative populations with the greatest genetic diversity. As an example from this study, the population from Fulong (FL) has a genetic 
diversity greater than that of the other populations, and it has diverse genotypes within population, thus, it should be a priority to consider its germplasm resources. Therefore, in order to conserve most genetic diversity of Hopea chinensis, further efforts should be made to strengthen on introduction for these two ex situ conservation. Our results indicated that seedlings introduction from Fulong (FL) population should be considered as a first option. It is also advisable to mix seeds or live plants collected from different populations for cross-breeding. These combinations might have potential for enhancing the genetic diversity of Hopea chinensis.

\section{Acknowledgements}

This study is supported by grants from Special Categorized Karst Plants Garden Construction (11217028), National Science and Technology Special Funds for Infrastructure Work Projects of China (2009FY120200) and Innovation and Capacity-building Project of Guangxi (11217028). Authors gratefully thank Xishuangbanna Tropical Botanical Garden, Chinese Academy of Science for providing samples, and grateful to Fangchenggang Forestry Bureau and Shiwan Mountain National Park for their kind assistance in field investigation.

\section{References}

Culley TM, Sbita SJ and Wick A 2007. Population genetic effects of urban habitat fragmentation in the perennial herb Viola pubescens (Violaceae) using ISSR markers. Ann. Bot. 100(1): 91-100.

Dai WJ, Tang WX, Deng T, Ding L, Luo WH and Huang SX 2011. Study on genomic total DNA extraction and purification of Hopea chinensis. Biotechnol. Bull. 7: 101-105.

Dai WJ, Tang WX, Deng T, Ding L, Luo WH and Huang SX 2011. Optimization for ISSR reaction system of Hopea chinensis by orthogonal design. Chin. Agric. Sci. Bull. 27(18): 143-147.

Frankham R, Ballou JD and Mcinnes KH 2002. Introduction to Conservation Genetics. Cambridge University Press, Cambridge, UK. pp. 266-276.

Huang SX, Chen H, Tang WX, Luo WH and Wang Y 2008. Biological and ecological characteristics of Hopea chinensis, a plant endemic to Guangxi. Biodivers. Sci. 16(1): 15-23.

IUCN 2006. Release of the 2006 IUCN Red List of threatened species reveals ongoing decline of the status of plants and animals. http://www.natureserve.

Nei M and Li WH 1979. Mathematical model for studying genetic variation in terms of restriction endonucleases. PNAS 76: 5269-5273.

Rohlf FJ 2000. NTSYS-pc version 2.1, Numerical Taxonomy and Multivariate Analysis System. Exeter Software, Setauket, New York.

Slatkin M and Barton NH 1989. A comparison of three indirect methods for estimating average levels of gene flow. Evol. 43: 1349-1368.

Tang WX, Mao SZ, Pan B, Huang SX, Mo L and Luo WH 2009. Spatial distribution pattern of seed rain and seed germ ination characteristics of endangered plant Hopea chinensis. J. Fujian Coll. For. 29(2): 97-102.

Wang CM, Huang SX and Wang Y 1994. The investigation and study on the germplasm resources of national precious, rare and endangered plants in Guangxi. GUIHAIA. 14(3): 278-283.

$\mathrm{Xu}$ ZF and Yu PH 1982. The low temperature adaptability investigation of the transplanted dipterocarpaceae plants. Acta. Bot. Yunnanica. 4(3): 298-300.

Yu YF 1999. The milestone of wild plants protection in China. Plant J. 5: 3-11.

Yeh FC, Yang RC and Boyle T 1999. POPGENE Version 1.31: Microsoft Window-based Free software for Population Genetic Analysis.

Yang Y, Pan YZ, Gong X and Fan MT 2010. Genetic variation in the endangered Rutaceae species Citrus hongheensis based on ISSR fingerprinting. Genet. Resour. Crop. Evol. 57: 1239-1248. 
Zhang L, Xiao CF and Wang J 2001. Ex situ conservation of Hopea chinensis. GUIHAIA. 21(3): 277-280.

Zhou TJ, Deng T, Tang WX, Mao SZ, Zhou LL, Xiong ZC and Huang SX 2013. Physiological responses of seedling of Hopea chinensis to PEG simulated drought stress. Huibei Agric. Sci. 52(24): 6079-6083.

Zietkiewicz E, Rafalski A and Labuda D 1994. Genome fingerprinting by simple sequence repeat (SSR) anchored polymerase chain reaction amplification. Genomics 20: 176-183.

Zhou ZH, Miwa M and Hogetsu T 1999. Analysis of genetic structure of a Suillus grevillei population in a Larix kaempferi stand by polymorphism of inter-simple sequence repeat (ISSR). New Phytol. 144(1): 55-63.

Zhang ZH, Zhou RC, Tang T, Huang YL, Zhong Y and Shi SH 2008. Genetic variation in central and peripheral populations of Excoecaria agallocha from Indo-West Pacific. Aquat. Bot. 89: 57-62.

Zou YP, Ge S and Wang XD 2001. Molecular Markers in Systematic and Evolutionary Botany. Science Press, Beijing. pp. 96-98.

(Manuscript received on 28 September, 2014; revised on 12 April, 2015) 